\title{
ARTICLE
}

\section{Analysis of the trinucleotide CAG repeat from the human mitochondrial DNA polymerase gene in healthy and diseased individuals}

\author{
A nja R ovio ${ }^{1}$, Valeria Tiranti ${ }^{2}$, A my L Bednarz ${ }^{3}$, A nu Suomalainen ${ }^{4}$, \\ Johannes N Spelbrink ${ }^{1}$, Nicolas L ecrenier ${ }^{5}$, A tle M elberg ${ }^{6}$, M assimo Z eviani ${ }^{2}$, \\ Joanna Poulton ${ }^{3}$, Françoise Foury ${ }^{5}$ and H oward T Jacobs ${ }^{1,7}$ \\ ${ }^{1}$ Institute of M edical Technology and Tampere U niversity H ospital, U niversity of Tampere, Finland \\ ${ }^{2}$ I stituto Nazionale N eurologico 'C B esta', M ilano, I taly \\ ${ }^{3} \mathrm{D}$ epartment of Pediatrics, University of Oxford, UK \\ ${ }^{4} \mathrm{D}$ epartment of Human M olecular G enetics, N ational Public $\mathrm{H}$ ealth Institute, $\mathrm{H}$ elsinki, Finland \\ ${ }^{5} U$ nité de B iochimie Physiologique, U niversité Catholique de L ouvain, B elgium \\ ${ }^{6} \mathrm{D}$ epartment of N euroscience, U niversity of U ppsala, Sweden \\ ${ }^{7}$ Institute of B iomedical and L ife Sciences, University of G lasgow, Scotland, UK
}

The human nuclear gene (PO LG ) for the catalytic subunit of mitochondrial D NA polymerase (DNA polymerase $\gamma$ ) contains a trinucleotide CAG microsatellite repeat within the coding sequence. We have investigated the frequency of different repeat-length alleles in populations of diseased and healthy individuals. The predominant allele of 10 CAG repeats was found at a very similar frequency (approximately $88 \%$ ) in both $F$ innish and ethnically mixed population samples, with homozygosity close to the equilibrium prediction. 0 ther alleles of between 5 and 13 repeat units were detected, but no larger, expanded alleles were found. A series of 51 B ritish myotonic dystrophy patients showed no significant variation from controls, indicating an absence of generalised CA G repeat instability. Patients with a variety of molecular lesions in mtD NA, including sporadic, clonal deletions, maternally inherited point mutations, autosomally transmitted mtD NA depletion and autosomal dominant multiple deletions showed no differences in PO L G trinucleotide repeat-length distribution from controls. These findings rule out PO L G repeat expansion as a common pathogenic mechanism in disorders characterised by mitochondrial genome instability.

Keywords: mitochondrial DNA ; mitochondrial myopathy; microsatellite; trinucleotide repeat; polyglutamine tract; DNA polymerase; deletions; progressive external ophthalmoplegia; myotonic dystrophy

Correspondence: Howard T Jacobs, Institute of Medical Technology, U niversity of Tampere, PO B ox 607, 33101 Tampere, Finland. Tel. or Fax: 3583215 7731; E-mail: howy.jacobs@uta.fi

R eceived $4 \mathrm{M}$ arch 1998; revised 5 J une 1998; accepted 19 J une 1998 


\section{Introduction}

Mitochondrial DNA (mtDNA) mutations are associated with a wide spectrum of human diseases ${ }^{1,2}$ and exhibit a variety of different types of inheritance. Clonal deletions or partial duplications of mtDNA typically manifest sporadically, whereas point mutations are usually maternally inherited. Two other kinds of mtDNA lesion appear to depend upon nuclear rather than mitochondrial genotype: mtDNA depletion $^{3-5}$ and multiple mtD NA deletions with autosomal dominant or recessive inheritance. ${ }^{6-9}$ A utosomal dominant progressive external ophthalmoplegia (ad-PEO) associated with multiple deletions of mtD NA is genetically heterogeneous, with mapped loci on chromosomes 3p14.1-21.2 and 10q24, and other affected families unlinked to either of these. ${ }^{7,8}$

$O$ ne candidate gene for involvement in mtDNA disorders showing nuclear inheritance is POL G, encoding the catalytic subunit of mitochondrial DNA polymerase (DNA polymerase $\gamma$ ). The gene has been mapped to the region of chromosome 15q24-15q26, ${ }^{10-12}$ and exhibits an unusual feature not shared with its orthologues in mouse, D rosophila or yeast, namely the presence of a trinucleotide (CAG) microsatellite repeat within the $\mathrm{N}$-terminal region of the coding sequence. ${ }^{11,13}$ The sequenced gene (Figure 1 ) contains 10 consecutive, glutamine-encoding CA G codons, followed by a single CAA and two further CA Gs. Instability at trinucleotide repeats is associated with various human disorders, including $\mathrm{H}$ untington's disease (HD), myotonic dystrophy (DM), and several forms of spinocerebellar atrophy (eg SCA 1). For review see La Spada ${ }^{14}$ and Koshy et al. ${ }^{15}$ Such disorders may be conveniently sub-classified according to where the repeat is found in relation to the coding sequence of the affected gene. Where the repeat is found in coding DNA, as here, such disorders are usually dominant, reflecting a gain of function associated with expanded repeat number. Expansions to 35 or more repeats are usually sufficient to create a pathological phenotype in such cases, eg in HD (see Wellington et al ${ }^{16}$ for review). Where the repeat is found outside coding DNA (eg in Friedreich ataxia), inheritance is usually recessive, reflecting loss of function, and repeat expansions can be, and usually are, much larger. Different repeatlength alleles of a single gene can be associated with distinct pathological phenotypes, for example in the case of the CA G repeat in the androgen receptor gene, where short 'normal' alleles are associated with enhanced predisposition to prostate cancer, ${ }^{17}$ long 'normal' alleles with androgen insensitivity, and expanded alleles ( $\geq 40$ repeats) with Kennedy's disease. Dominant disorders characterised by repeat expansion also exhibit the phenomenon of anticipation: the progressive increase in repeat length and in disease severity from generation to generation.

Expansion of the POLG CAG repeat would be a plausible disease mechanism in disorders characterised by mtDNA instability inherited as an autosomal trait, since expansion of the polyglutamine tract might impair the function of the mitochondrial DNA polymerase in a dominant-negative manner. Interestingly, anticipation has been reported in one family with ad-PE $O$ unlinked to the mapped ad-PEO loci on chromosomes $3 p$ or 10q. ${ }^{18} \mathrm{~A}$ modest polyglutamine expansion might also be associated with apparently sporadic cases of mtDNA rearrangement, or might even promote the mutational events that manifest subsequently as diseases associated with inherited point mutations of mtDNA. In addition, dysfunction of the mitochondrial DNA polymerase not associated with repeat size might be of pathological significance. $R$ epeat-length variation in the POLG gene might therefore provide a useful linkage marker for evaluating the involvement of the gene in diverse human disorders.

In order to investigate the possible role of the POL G gene in human disease, we have studied repeat-length variation at the locus, both in healthy populations and in various groups of patients. 0 ur aim was to look both for gross expansions associated with disease, as well as to examine possibly more subtle relationships between POLG repeat-length and pathological phenotype. The results indicate that $P O L G$ repeat expansion cannot be a frequent cause of mitochondrial disease. Diversity at the POLG locus is also lower than optimal for use generally as a linkage marker, but sufficient that the gene can be excluded in specific cases.

\section{Results and Discussion}

Nested primers flanking the POL G CA G repeat were designed, based on a region of the coding sequence ${ }^{11,13}$ contained within a single exon (see Figure 1). The primers amplified the predicted fragments from genomic DNA (Figure 1), as verified by direct sequencing. Testing against the monochromosomal inter-species hybrid and Genebridge 4 radiation hybrid panels ${ }^{19}$ confirmed that they detected only the expected gene sequence from chromosome $15 q$, and not a pseudogene 
301 AGGAAGGTGGCCGGCGCCACCGTCGGGCCAGGGCCGGTTCCAGCTCCGGGGCGCTGGGTC

$\operatorname{mip} 51$

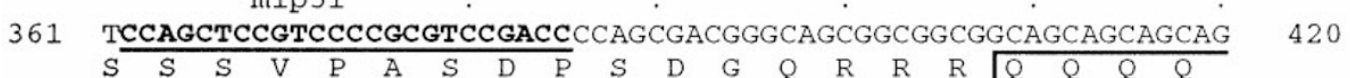

421 . mip31 complement

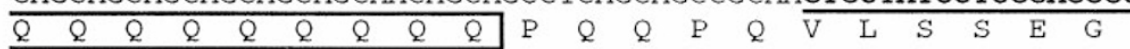

mip32 complement

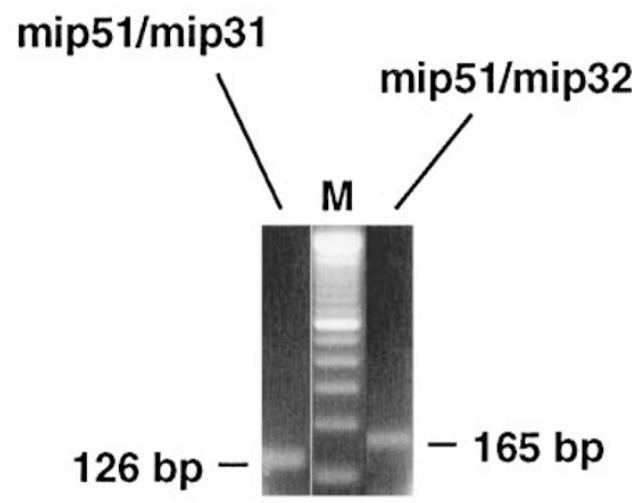

(b)

Figure1 (a) Partial sequence of the human gene for the catalytic subunit of the mitochondrial DNA polymerase (POLG), from Genbank data entry MIHSD NAPL (accession number X98093), numbered as in the database The N-terminus of the coding region is shown in the oneletter amino acid code, with the polyglutamine tract boxed. The sequences corresponding to the PCR primers used here (or their complement) are bold, underlined. (b) $2.5 \%$ agarose gel of PCR products made using primer pairs mip51/mip31 and mip51/mip32, on human genomic DNA template 
(data not shown). The 5' primer (mip51) was also tested with other, more downstream 3 ' primers from the same exon of the POLG gene, successfully and routinely amplifying genomic DNA fragments up to $0.6 \mathrm{~kb}$ in size (data not shown). This indicates that even grossly expanded CA G repeats (eg of the order of 150) would be detectable.

POLG trinucleotide repeat-length was then evaluated in two groups of healthy controls, plus a number of patient groups, as shown in Table 1, using a fluorescence-based PCR method. ${ }^{20}$ G enotype was also confirmed in many cases by direct sequencing of $P C R$ products or by cloning. The previously reported variant of 10 repeats ${ }^{11,13}$ was found much more frequently than any other allele. In an ethnically diverse sample of 73 unrelated, healthy persons, it was found at a frequency of $88 \%$. In a sample of 61 unrelated, healthy Finns, a genetically isolated and bottlenecked population that has been much exploited in disease linkage studies, the frequency of the common allele was almost the same $(89 \%)$. Several groups of patients were also studied, including a series of 51 unrelated D M patients from the $U K$, and a group of 12 unrelated Chinese patients with acute aminoglycoside ototoxicity ( $A \mathrm{~A} O$ ), one of whom had the np $1555 \mathrm{mtDNA}$ mutation. The frequency of the common (10-repeat) allele was not significantly different ( $z$-test, $P>0.05$ ) in any group studied, nor was any evidence found for an association between a specific, unusual allele and any of the patient groups investigated. A mongst DM patients, there was fur- thermore no correlation between disease severity and POLG genotype. The overall frequency of the 10-repeat allele in 214 ethnically diverse, unrelated individuals included in the study was $88 \%$. The next commonest allele was of 11 repeats (7\%), with other, rarer alleles ranging from 5 to 13 repeats comprising the remainder. Observed homozygosity values for the common allele are close to equilibrium predictions.

No expanded alleles were observed in healthy controls or in any of the patient groups studied, including the $51 \mathrm{DM}$ subjects. This rules out POLG repeat expansion as a contributory factor in $D M$, and is consistent with repeat instability being locus-specific in this disorder. Expanded alleles were also absent from diverse patients with mtD NA disorders, as summarised in Table2. These results do not exclude the possibility of very large expansions undetectable by conventional $P C R$, but coding region expansions of the type found in other disorders (i.e. up to several hundred copies) would have been easily observed. Expansions in the CAG repeat of the DMPK gene of over 500 repeat units were easily detected in DM patient DNAs, using primers that amplify a similarly sized (165 bp) fragment spanning the repeat, and otherwise identical materials and methods (data not shown). Most patients we studied were homozygous for the common POLG allele, (except where stated in Table2), but heterozygotes were found amongst several patient groups, in which cases it is possible to exclude even very large expansions undetectable by PCR .

Table 1 A llele frequenciesa at the PO L G trinucleotide repeat in different populations

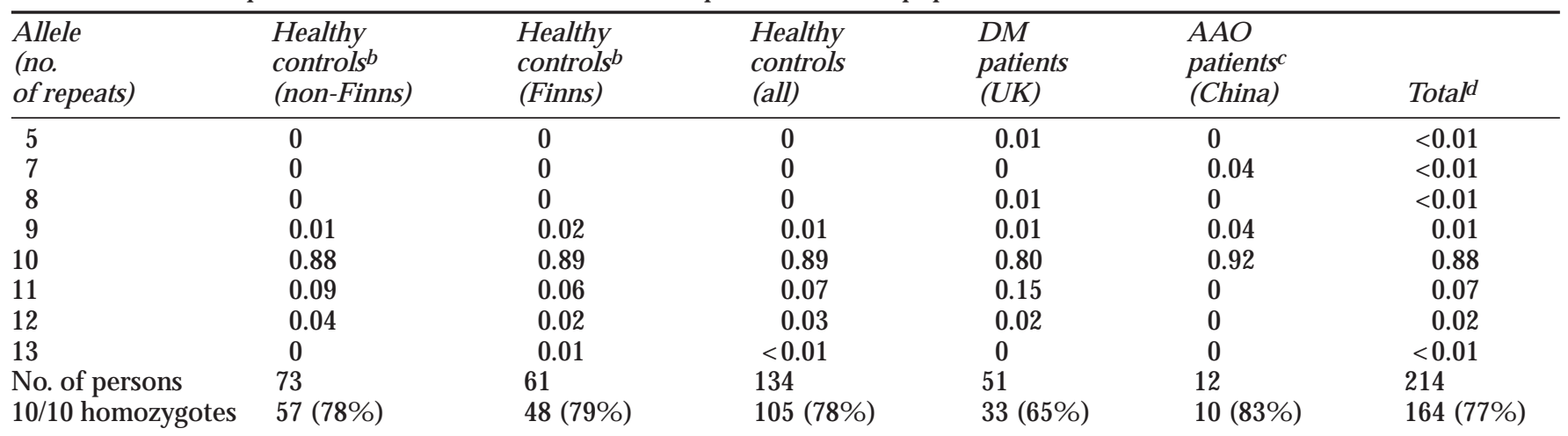

aA II allele frequencies quoted to 2 decimal places, except where rounding would give 0.00 , which is quoted as $<0.01$. Therefore, not all columns total 1.00 .

bH ealthy controls had no hearing impairment and reported no manifestations of systemic disease.

cO nly 12 Chinese patients with acute aminoglycoside ototoxicity (A A O) were included, hence the reported allele frequencies of 0.04 represent single alleles in two heterozygotes.

dThe final column includes 17 individuals not listed under any other category. Hence the total of 214 persons is greater than the sum of controls, U K D M patients and chinese A A O patients. The additional persons were one hearing-impaired individual, plus 16 English patients with various mitochondrial and non-mitochondrial disorders. 
Table 2 Exclusion of POL G CA G repeat expansion in cases of mtD NA disorders

\begin{tabular}{|c|c|c|c|c|}
\hline Clinical phenotype & Molecular phenotype & $\begin{array}{l}\text { Literature } \\
\text { reference }\end{array}$ & $\begin{array}{l}\text { No. of } \\
\text { patients } \\
\text { studied }\end{array}$ & Comment \\
\hline ad-PE O & multiple mtD NA deletions & 8 & 3 & $\begin{array}{l}\text { no linkage to ad-PE } 0 \text { loci on chromosomes } \\
3 p \text { or } 10 q\end{array}$ \\
\hline ad-PE O & multiple mtD NA deletions & 7 & 2 & Finnish family linked to chromosome 10 q24 \\
\hline ad-PEO with anticipation & multiple mtD NA deletions & 18 & 2 & $\begin{array}{l}\text { Swedish family, no linkage to ad-PE O loci } \\
\text { on chromosomes } 3 p \text { or } 10 q\end{array}$ \\
\hline PE O & single mtD NA macrodeletion & 24 & 10 & sporadic cases \\
\hline $\begin{array}{l}\text { infantile mt myopathy } \\
\text { with COX deficiency }\end{array}$ & mtD NA depletion & 25,26 & $\begin{array}{l}3, \text { plus } \\
\text { unaffected } \\
\text { relatives }\end{array}$ & $\begin{array}{l}\text { mtD NA depletion verified in muscle and/or } \\
\text { liver: one I talian, two E nglish patients }\end{array}$ \\
\hline $\begin{array}{l}\text { infantile mt myopathy } \\
\text { with COX deficiency }\end{array}$ & suspected mtD NA depletion & 26 & 3 & E nglish patients described in $\mathrm{H}$ olt et al 24 \\
\hline $\begin{array}{l}\text { fatal neonatal hepatic } \\
\text { failure }\end{array}$ & mtD NA depletion in liver & 5 & $\begin{array}{l}2, \text { plus } \\
\text { unaffected } \\
\text { relatives }\end{array}$ & $\begin{array}{l}\text { consanguineous family described in } \\
\text { B akker et al, } 5 \text { heterozygous }\end{array}$ \\
\hline MELAS & np 3243 point mutation & 27,28 & 2 & $\begin{array}{l}\text { plus } 36 \text { unaffected maternal relatives from } \\
\text { Finnish and English pedigrees with the } \\
\text { mutation }\end{array}$ \\
\hline MERR F & np 8344 point mutation & 29 & 2 & \\
\hline N on-syndromic deafness & np 1555 mutation & 30 & 16 & $\begin{array}{l}\mathrm{H} \text { ispanic pedigrees with the mutation; total } \\
\text { includes } 8 \text { unaffected maternal relatives; } \\
7 \text { heterozygotes }\end{array}$ \\
\hline NAR P & np 8993 & 31 & 1 & from UK \\
\hline
\end{tabular}

Genotyping of the POLG repeat furthermore enabled us to exclude the locus from further consideration in the case of the family with hepatic mtDNA depletion, assuming autosomal recessive inheritance. ${ }^{21}$ Linkage studies have also excluded the POLG region of chromosome $15 \mathrm{q}$ from involvement in ad-PEO in Finnish, Italian and Swedish families in which it is unlinked to the previously mapped loci on chromosomes 3 or 10 (A Suomalainen 1998, unpublished data).

The amount of heterozygosity at the POL G repeat is probably too low to enable it to be employed as a useful marker in disease linkage studies generally, although it will have utility in specific cases. The fact that a similar pattern of variation is evident in widely scattered populations suggests the possibility of selection, acting to drive the repeat length down (or up) to the modal value of ten CA G repeats. However, all other alleles found amongst patients were also found in controls, hence there is no evidence for association of particular repeat-length variants with any given pathological phenotype.

\section{Methods}

\section{DNA Samples}

DNA was obtained from blood or muscle biopsy of healthy controls and patients, as described previously, ${ }^{22}$ but with proteinase $\mathrm{K}$ inactivated by incubation at $92^{\circ} \mathrm{C}$ for $10 \mathrm{~min}$. A II the samples were taken with informed consent. D NA from Chinese patients with acute aminoglycoside ototoxicity was kindly donated by $\mathrm{Dr}$ W-Q Q iu (Tiedao M edical College, Shanghai, China), from UK myotonic dystrophy patients by $\mathrm{Dr}$ Helen Harley (U niversity of Wales, Cardiff), from Spanish subjects with the np $1555 \mathrm{mtDNA}$ mutation by Dr Ignacio del Castillo (H ospital Ramón y Cajal, Madrid, Spain), and from members of Finnish pedigrees carrying the 
np 3243 mtD NA mutation by Dr K ari Majamaa (U niversity of Oulu, Finland). DNA samples for the Genebridge 4 radiation hybrid panel ${ }^{19}$ and the monochromosomal human-rodent hybrid panel were supplied by the UK MRC HGMP Resource Centre, Cambridge.

\section{Oligonucleotide primers}

$\mathrm{N}$ ested oligonucleotides corresponding to regions of the $\mathrm{N}$-terminal coding sequence of $\mathrm{PO} \mathrm{LG}$, as indicated in Figure 1, were purchased from Life Technologies (Paisley, Scotland) or D NA Technology (A arhus, D enmark). For fluorescent $P C R^{20}$ one of the primers (mip51) was $5^{\prime}$ pre-labelled with ROX (Perkin-EImer dye) by the manufacturer.

\section{PCR}

U nlabelled PCR reactions used primer pairs mip51/ mip31 (126 bp product from reference sequence) or mip51/mip32 (165 bp product) at $0.8 \mu \mathrm{M}$ each, $200 \mu \mathrm{M}$ dNTPs (A mersham Pharmacia Biotech, U ppsala, Sweden), plus 0.25 units of $D$ ynazyme thermostable DNA polymerase (Finnzymes, Espoo, Finland) in the manufacturer's buffer. Reactions comprised 30 cycles of denaturation for $1 \mathrm{~min}$ at $95^{\circ} \mathrm{C}$, annealing for $45 \mathrm{~s}$ at $62^{\circ} \mathrm{C}$, and extension for $2 \mathrm{~min}$ at $72^{\circ} \mathrm{C}(5 \mathrm{~min}$ extension in final cycle). Products were analysed by agarose or polyacrylamide gel electrophoresis. For fluorescent PCR, $12.5 \mu \mathrm{l}$ reactions contained $0.2 \mu \mathrm{m}$ each primer, $200 \mu \mathrm{m}$ dNTPs (A mersham Pharmacia Biotech, Uppsala, Sweden), $0.5 \mu$ of DNA template ${ }^{22}$ and 0.16 units of $D$ ynazyme thermostable DNA polymerase (Finnzymes, Espoo, Finland) in the manufacturer's buffer, and used the same cycle conditions, except the extension step which was for 1 min only. Reaction products were diluted 1:10 in water, and samples containing $1 \mu \mathrm{l}$ of diluted PCR product, $12 \mu \mathrm{l}$ of deionised formanide and $0.15 \mu$ of Tamra Genescan350 D NA size standards (Perkin-E Imer, N orwalk, CT, U SA ) were analysed on the A BI $310 \mathrm{G}$ enetic $A$ nalyzer (Perkin-EImer, Norwalk, CT, USA ), using the manufacturer's data collection and Genescan analysis software. ${ }^{20,23}$

\section{Cloning and cycle sequencing}

U nlabelled PCR products were purified on Q IA quick spin columns ( $Q$ iagen). Cloning used the TA-cloning kit (Invitrogen), and insert-containing plasmids were identified by miniprepping and E coR I digestion. Cycle sequencing employing the $\mathrm{A} B \mathrm{~B} 310 \mathrm{G}$ enetic $\mathrm{A}$ nalyzer used the Terminator Ready Reaction $K$ it (Perkin-
Elmer), together with unlabelled mip51 primer (direct sequencing of PCR products) or M 13 reverse primer (plasmid sequencing).

\section{Acknowledgements}

We thank Kari M ajamaa, Ignacio del Castillo, Wei-Q in Qiu, $\mathrm{H}$ elen $\mathrm{H}$ arley and Peter $\mathrm{H}$ arper for supplying D NA samples, E rkki M äkelä for statistical analysis, plus the many patients and healthy controls who took part in the study. Funding for this work was obtained from the Royal Society (U niversity R esearch Fellowship to J P), Wellcome Trust, B ritish D iabetic A ssociation, Finnish A cademy, M uscular D ystrophy $G$ roup of Great Britain, Juselius Foundation, Tampere U niversity Hospital M edical R esearch Fund, I talian Telethon Foundation (grant no. 767 to M Z) and the E uropean U nion H uman Capital and Mobility programme.

\section{References}

1 Larsson NG, Clayton DA: Molecular genetic aspects of human mitochondrial disorders. A nnu Rev G enet 1995; 29: 151-178.

2 Fadic R, Johns DR: Clinical spectrum of mitochondrial diseases. Seminars Neurol 1996; 6: 1-20.

3 Moraes CT, Shanske S, Tritschler $H J$ et al: M tDNA depletion with variable tissue expression: a novel genetic abnormality in mitochondrial diseases. A m J Hum Genet 1991; 48: 492-501.

4 Bodnar A G, Cooper J M, Holt IJ, Leonard JV, Schapira $\mathrm{AH}$ : N uclear complementation restores mtDNA levels in cultured cells from a patient with mtDNA depletion. A m J H um G enet 1993; 53: 663-669.

5 Bakker HD, Scholte HR, D ingemans KP, Spelbrink JN, Wijburg FN, Van den Bogert C: D epletion of mitochondrial deoxyribonucleic acid in a family with fatal neonatal liver disease. J Pediatr 1996; 128: 683-687.

6 Zeviani M, Bresolin N, Gellera C et al: Nucleus-driven multiple large-scale deletions of the human mitochondrial genome: a new autosomal dominant disease. A m J H um G enet 1990; 47: 904-914.

7 Suomalainen A, Kaukonen J, A mati $P$ et al: A $n$ autosomal locus predisposing to deletions of mitochondrial DNA. $\mathrm{N}$ at $\mathrm{G}$ enet 1995; 9: 146-151.

$8 \mathrm{~K}$ aukonen JA, A mati $P$, Suomalainen $A$ et al: $A n$ autosomal locus predisposing to multiple deletions of mtD NA on chromosome 3p. A m J Hum G enet 1996; 58: 763-769.

9 Bohlega S, Tanji K, Santorelli FM, H irano M, al-J ishi A, Di Mauro S: Multiple mitochondrial DNA deletions associated with autosomal recessive ophthalmoplegia and severe cardiomyopathy. N eurology 1996; 46: 1329-1334.

10 Walker R L, A nziano P, M eltzer PS: A PA C containing the human mitochondrial DNA polymerase gamma gene (POL G) maps to chromosome 15q25. G enomics 1997; 40: 376-378.

11 R opp PA, Copeland W C: Cloning and characterization of the human mitochondrial DNA polymerase, DNA polymerase gamma. G enomics 1996; 36: 449-458. 
12 Zullo SJ, Butler L, Z ahorchak RJ, M acVille M, Wilkes C, Merril CR: Localization by fluorescence in situ hybridization (FISH) of human mitochondrial polymerase $\gamma$ $(P O L G$ ) to human chromosome band $15 q 24 \rightarrow 15 q 26$, and of mouse mitochondrial polymerase $\gamma$ (Polg) to mouse chromosome band $7 \mathrm{E}$, with confirmation by direct sequence analysis of bacterial artificial chromosomes (BA C s). Cytogenet C ell G enet 1997; 78: 281-284.

13 L ecrenier N, Van D er B ruggen P, Foury F : M itochondrial DNA polymerases from yeast to man: a new family of polymerases. G ene 1997; 185: 147-152.

14 La Spada A R: Trinucleotide repeat instability: genetic features and molecular mechanisms. Brain Pathol 1997; 7: 943-963.

15 Koshy BT, Zoghbi HY: The CAG/polyglutamine tract diseases: gene products and molecular pathogenesis. B rain Pathol 1997; 7: 927-942.

16 Wellington $C L, B$ rinkman $R R, O$ 'Kusky J R, H ayden $M R$ : Toward understanding the molecular pathology of $\mathrm{H}$ untington's D isease. Brain Pathol 1997; 7: 979-1002.

17 G iovannucci E, Stampfer MJ, K rithivas K et al: The CA G repeat within the androgen receptor gene and its relationship to prostate cancer. Proc Natl A cad Sci USA 1997; 94: 3320-3323.

18 Melberg $A$, A rnell $H, D$ ahl $N$ et al: A nticipation of autosomal dominant progressive external ophthalmoplegia with hypogonadism. Muscle Nerve 1996; 19: 1561-1569.

19 G yapay G, Schmitt K, Fizames $C$ et al: A radiation hybrid map of the human genome. Hum Mol Genet 1996; 5: 339-346.

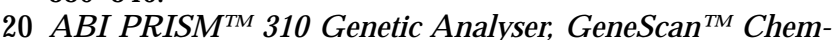
istry G uide. Perkin E Imer Corporation: July 1995.

21 Spelbrink J N, Van Galen MJ M, Z wart R et al: Familial mitochondrial DNA depletion in liver: haplotype analysis of candidate genes. $\mathrm{H}$ um $\mathrm{G}$ enet 1998; 102: 327-331.

22 Reid FM, Vernham GA, Jacobs HT: A novel mitochondrial point mutation in a maternal pedigree with sensorineural deafness. Hum Mutat 1994; 3: 243-247.
23 Wenz H, R obertson J M, M enchen S et al: High-precision genotyping by denaturing capillary electrophoresis. G enome Res 1998; 8: 69-80.

$24 \mathrm{H}$ olt IJ, $\mathrm{H}$ arding $\mathrm{A} \mathrm{E}, \mathrm{M}$ organ-H ughes JA : Deletions of muscle mitochondrial DNA in patients with mitochondrial myopathies. Nature 1988; 331: 717-719.

25 Mariotti C, Uziel G, Carrara F et al: Early onset encephalomyopathy associated with tissue-specific mitochondrial DNA depletion - a morphological, biochemical and molecular genetic study. I Neurol 1995; 242: 547-556.

26 Poulton J, Sewry C, Potter CG et al: Variation in mitochondrial DNA levels in muscle from normal controls. Is depletion of mitochondrial DNA in patients with mitochondrial myopathy a distinct clinical syndrome? J Inherit M etab D is 1995; 18: 4-20.

27 G oto $Y$, N onaka I, H orai S: A mutation in the tR NA L eu (UUR) gene associated with the MELAS subgroup of mitochondrial encephalomyopathies. Nature 1990; 348: 651-653.

28 Kobayashi $Y$, Momoi $M Y$, Tominaga $K$ et al: A point mutation in the mitochondrial tR NA ${ }^{\text {Leu }}(\cup \cup R)$ gene in MELA S (mitochondrial myopathy, encephalopathy, lactic acidosis and stroke-like episodes). B iochem Biophys R es Comm 1990; 173: 816-822.

29 Shoffner J M, L ott M T, L ezza A M, Seibel P, B allinger SW, Wallace $D C$ : M yoclonic epilepsy and ragged-red fiber disease (MERRF) is associated with a mitochondrial DNA tR NA Lys mutation. Cell 1990; 61: 931-937.

30 Prezant TR, A gapian JV, Bohlman MC et al: M itochondrial ribosomal RNA mutation associated with both antibiotic-induced and non-syndromic deafness. $\mathrm{N}$ at $\mathrm{G}$ enet 1993; 4: 289-294.

$31 \mathrm{H}$ olt IJ, Harding A E, Petty R K H, M organ-H ughes JA : A new mitochondrial disease associated with mitochondrial D NA heteroplasmy. A m J H um G enet 1990; 46: 428-433. 